\title{
Levels And Risks of Antineoplastic Drugs In Households of Oncology Patients, Hospices And Retirement Homes
}

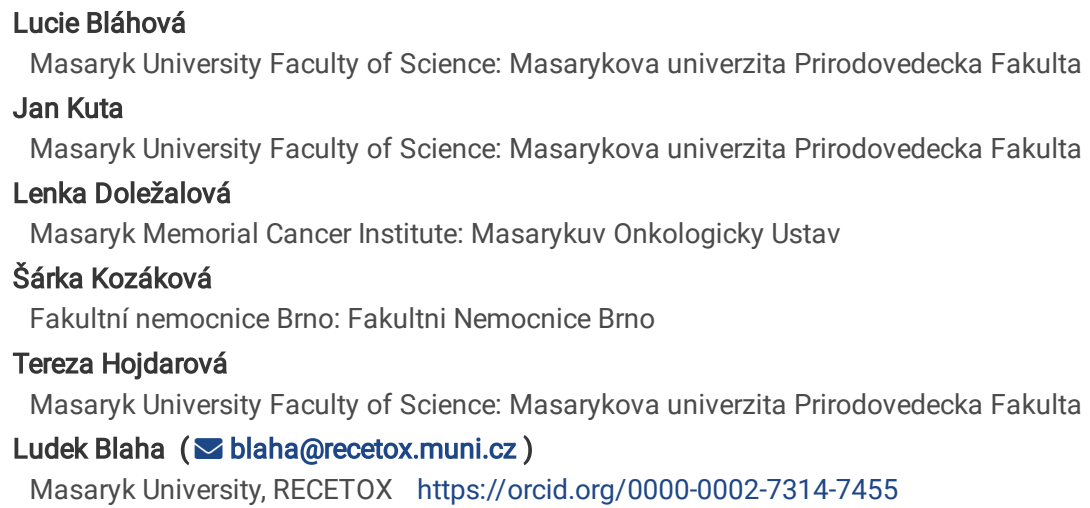

Research

Keywords: Hazardous drugs, Surface contamination, Antineoplastic drugs, Cyclophosphamide, Patient homes

Posted Date: June 15th, 2021

DOl: https://doi.org/10.21203/rs.3.rs-589987/v1

License: (c) (1) This work is licensed under a Creative Commons Attribution 4.0 International License. Read Full License 


\section{Abstract}

Background

Contamination of the indoor environment by the antineoplastic drugs (ADs) is known to pose health risks to the exposed staff in hospitals or pharmacies. ADs may also contaminate households of the patients receiving chemotherapy but the exposure levels and potential risks to family members have not been studied. The objective was to provide an in-depth research of surface contamination by ADs inside homes focusing on the households of oncology patients, hospices and retirement houses.

Results

The main study included repeated samplings of surfaces (floors, desktops) in households of 17 ambulant oncology patients receiving different chemotherapies with cyclophosphamide (CP), platinum-based drugs (Pt), doxorubicin (DOX), 5-fluorouracil (FU) and others. Screening of AD contamination was further performed in 2 hospices and 2 retirement homes. The wipe samples were analyzed by HPLC-MS/MS and ICP-MS/MS for 11 organic ADs and total Pt as a marker of Pt-based ADs. Patients treated with chemotherapy were found to serve as a source of contamination for their households, representing thus a risk to sensitive family members such as children or elderly people. Carcinogenic $\mathrm{CP}$ was commonly found at relatively high concentrations, especially during the first 6 days after the chemotherapy (maximum $511 \mathrm{pg} / \mathrm{cm} 2$ ). Sweat seems to be a major medium for the spread of the contamination, and high and long-time persisting CP levels (traces still found after 6 months post-chemotherapy) were found on various desktops including kitchen dining tables. The pilot studies in hospices and retirement homes indicated rather lower exposure risks of the personnel but pointed to potential long-lasting contamination by Pt or some other persistent ADs such as ifosfamide, IF.

Conclusions

This is one of the first studies investigating the contamination by ADs in indoor environments outside of hospitals or pharmacies. Peak concentrations of the carcinogenic CP in households were comparable to those observed in hospitals. The information guidance flier with practical recommendations was prepared improving thus information as well as prevention of eventual risks for family members.

\section{Introduction}

Various antineoplastic drugs (ADs) are used in large quantities not only as anti-cancer chemotherapies but also as immune suppressants or anti-rheumatic agents etc. (Kümmerer et al., 2016). The still increasing usage patterns of ADs raised concerns for healthcare workers in the pharmacies and hospitals (Connor and McDiarmid, 2006; Dranitsaris et al., 2005; NIOSH, n.d.), and the occupational exposures have been associated with adverse health outcomes in exposed personnel including reproduction toxicity or cancer (IARC; European Commission, 2019) (Cherrie et al., 2017; NIOSH, n.d.). ADs are also discussed as compounds of environmental relevance (Kümmerer et al., 2016), and widespread contamination indoor and outdoor has been extensively studied (Blahova et al., 2020; Fleury-Souverain et al., 2015; Kiffmeyer et al., 2013; Kopp et al., 2013; Odraska et al., 2014; Roland et al., 2017; Sottani et al., 2017).

ADs are chemically diverse compounds that act through various mechanisms and differ in the overall consumption and use. The Supplementary Table S1 summarizes the information on the preparations of ADs in the Czech Republic. A survey of 18 out of 47 pharmacies that have official permission to handle ADs showed that few ADs - cyclophosphamide (CP), platinum-based drugs (Pt), 5-fluorouracil (FU), paclitaxel (PX), gemcitabine (GEM), irinotecan (IRI), ifosfamide (IF) and methotrexate (MET) - are prepared in the large quantities and together comprise $25-80 \%$ of all AD preparations with the overall average of $51 \%$. In agreement with previous studies, this shows the high importance of few ADs, namely CP, FU and Pt-based compounds as the representative biomarkers of exposures to ADs (Jeronimo et al., 2015; Kopp et al., 2013; Turci et al., 2003).

The exposures to ADs are most commonly assessed indirectly by analyzing the contamination of surfaces such as floors, desktops, handles, etc. (Astrakianakis et al., 2020), and naturally, the majority of the information is available for pharmacies and medical facilities (Blahova et al., 2020; FleurySouverain et al., 2015; Kiffmeyer et al., 2013; Kopp et al., 2013; Odraska et al., 2014; Roland et al., 2017; Sottani et al., 2017). As documented in the literature, surface contamination is highly variable within and between different oncology departments or pharmacies (Chauchat et al., 2019; Odraska et al., 2014). The contamination range from non-detected contamination (low pg/ $\mathrm{cm}^{2}$ ) up to $100 \mathrm{ng} / \mathrm{cm}^{2}$ (documented for CP and FU) or up to $10 \mathrm{ng} / \mathrm{cm}^{2}$ (Pt-based drugs cis-, carbo- or oxali-Pt) (Astrakianakis et al., 2020; Kopp et al., 2013; Schierl et al., 2009; Turci et al., 2003). Generally, the most frequently and highly contaminated surfaces in the patient care units are the intravenous poles and the floor beneath the infusion stand, surfaces in the toilets and bathrooms, and the areas where chemotherapy infusions or body fluids of patients are handled (Astrakianakis et al., 2020; Kopp et al., 2013; Schierl et al., 2009; Turci et al., 2003).

Concerning the genotoxic action of many ADs, no official exposure limits are available. It is recommended to keep the exposures as low as reasonably achievable. Some studies, however, recommended the use of the individual threshold guidance values (TGV) based on large scales monitoring studies, where TGVs are the statistical values such as the 75th or 90th percentile of the collected data set (Kiffmeyer et al., 2013; Schierl et al., 2009). Alternatively, based on the results of biomonitoring results (CP levels in the urine of nurses), surface TGVs for CP were suggested to be $0.1 \mathrm{ng} / \mathrm{cm}^{2}$ (the acceptable surface concentration safe for work) and $10 \mathrm{ng} / \mathrm{cm}^{2}$ (prohibitory value triggering stop of the work and remediation actions) (Sessink, 2011). Further, it was suggested that for CP, which is a confirmed carcinogen class I (IARC; European Commission, 2019), the contamination below $1 \mathrm{ng} / \mathrm{cm}^{2}$ should be protective for the health care personnel (Gabay, 2014).

The most relevant uptake route of ADs into the professional staff is the transdermal absorption after the skin contact with contaminated surfaces (Kromhout et al., 2000; Power et al., 2018). Correspondingly, wearing personal protective equipment such as gloves is the most important risk mitigation measure. In

Page 2/10 
addition to skin contact with contaminated surfaces, other routes of exposure have been found highly relevant in the healthcare setting including handling bedding with sweat and body fluids of the patients (Fransman et al., 2005; Hon et al., 2015; Meijster et al., 2006).

In recent years, the administration of chemotherapy is shifting from controlled hospital healthcare that complies with recommended safety regulations (NIOSH, n.d.) (ISOPP 2007) to much less controlled setting such as outpatient departments (where the patients spent only a few hours) or to households of the patients. Typically, $80 \%$ of total ADs are administrated intravenously - mostly in hospitals or other medical facilities, about $20 \%$ can be administered orally (Kümmerer et al., 2016), and various types of take-home anticancer therapies have become a standard for many patients because of the reduced costs and higher patient satisfaction (Pardhan et al. 2021).

However, the information about the occurrence and levels of ADs outside of the hospitals or pharmacies, i.e. the contamination of surfaces in patient homes are very rare. To our knowledge, there are only three studies that quantified AD contamination in households. Pilot studies from Japan monitored CP and 5-FU in home environments (Yuki et al. 2013), and further extended towards biomonitoring of patients and their family members (Yuki et al., 2015). Also, another study addressed contamination and risks of CP, FU, and Pt residues to families of oncology patients (Böhlandt et al., 2017).

The objectives of the present study were to provide an in-depth research of surface contamination by ADs inside homes focusing on the households of oncology patients (repeated samplings at 17 ambulant oncology patients receiving different chemotherapies), where CP, FU, Pt, doxorubicin (DOX), epirubicin (EPI), IRI, PX were monitored during active chemotherapy, and also after an extended period of six or more months after the last chemotherapy treatment. Further, the present study included a screening of contamination by twelve ADs (CP, FU, Pt, PX, DOX, EPI, IRI, capecitabine (CAP), MET, docetaxel (DOC), GEM) in 2 hospices and 3 retirement homes to get the first insights into potential secondary exposures of the clients and nursing staff.

\section{Material And Methods}

\subsection{Chemicals and reagents}

Analytical standards and solvents were obtained from Toronto Research Chemicals (TRC) or Sigma-Aldrich, British Pharmacopoeia Chemical Reference Substances (BPCRS), Analytika (Czech Republic), Suprapur (Merck), and Biosolve BV. More details are provided in Supplementary materials. Quality control sample for validation of extraction during long term monitoring was prepared in methanol and contained $\mathrm{CP}(3.6 \mathrm{ng} / \mathrm{mL}), \mathrm{Pt}$ (sum of carbo-, oxali- and cis-Pt; $3.6 \mathrm{ng} / \mathrm{mL}), \mathrm{FU}(7.2 \mathrm{ng} / \mathrm{mL})$ and $\mathrm{PX}(4.6 \mathrm{ng} / \mathrm{mL})$. Field blanks were routinely included during the study.

2.2 Study design

The study included monitoring in homes of patients undergoing active chemotherapy, in hospices, and in retirement homes during 2019-2021. Seventeen adult patients of the Masaryk Memorial Cancer Institute hospital in Brno, CZ, were enrolled and gave their written consent (Table 1). The patients had a good prognosis and received intravenous chemotherapies containing CP, DOX, EPI, IRI, FU, PX or Pt-based ADs. We focused on CP and Pt treatments because of their high frequency and amounts used in the Czech Republic, and considering hazardous and pharmacokinetics properties when relatively high unmetabolized amounts are released in human excretion (Bláhová et al., 2021).

Before the large study at 17 patients, detailed screening was performed at patient No. 1, where surface samples were taken before the first treatment (blank), and four times during the complete therapy plan during 2019-2020. Based on the results of this pilot study, two sampling campaigns were planned for each patient. First samplings were conducted within few first days after the chemotherapy cycle of CP or PX (see Table 1 which indicates days of sampling after the last administered AD cycle). The second control sampling was done 6 months or later after the last cycle of chemotherapy. This second sampling was conducted only at the patients that were found positive in the first sampling campaign. The exception were three other patients (No. 12, 15 and 16 ), where the 2nd sampling was not possible because of their worsened prognoses.

Fifteen of the patients were females with diagnosed breast cancer that received bolus i.v. doses in 4 cycles of CP and DOX during three weeks period that was followed by PX treatment at 11 patients (6 to 15 weekly cycles of PX) and carbo-Pt treatment at two patients (10 cycles). Four patients with the initial CP treatment did not receive follow-up PX or carbo-Pt treatments. One patient (No. 13, female, breast cancer) received 4 cycles of $\mathrm{CP}$ and EPI during three weeks period followed by 12 weekly cycles of PX. All treatments were administrated through an outpatient service at the Masaryk Memorial Cancer Institute in Brno, Czech Republic, and the patients were released home immediately after the chemotherapy administration. One patient (No. 16, male, pancreatic cancer) received a single treatment containing FU, IRI and oxali-Pt at home using a 48-h continuous infusion pump.

The median age of the sixteen enrolled female patients with similar breast cancer diagnoses was 43 (ranging 34-73 years; Table 1). All participants were asked to answer the questionnaire with information about family members, pets, number of bathrooms, frequency and types of common house cleaning procedures. The outcomes of the survey are in Supplementary Table S2. Overall, 15 participants lived in a city and 2 in a village, the mean number of household members was 3.4, 10 participants lived together with small children. Four participants had more than one toilet or bathroom in their homes. The participating households reported daily cleaning of a kitchen and cleanings of bathrooms once or twice a week using detergents and antimicrobial agents (Supplementary Table S2). Eight participants used also an oxidizing agent during cleaning and nine reported the use of protective gloves.

Beyond the study of ADs in the patient homes, we performed screening of contamination by 12 ADs in two hospices (50 and 20 beds) and three retirement homes (105, 104 and 140 beds), where former chemotherapy patients lived and possible contamination could eventually persist. The monitored hospices served oncology patients only in palliative care. We performed screening of 10 places including floors in bathrooms, toilets, and rooms of former oncology patients as well as places for nurses, sanitary rooms, and kitchens. The retirement homes rarely provided care to oncology patients, the managements reported between 1 to 3 patients per year. We assessed 19 places including floors in bathrooms, sanitary rooms, toilets, laundry as well as surfaces in resident rooms such as the floor in front of the bed, kitchen tables, etc. 
The studied surfaces in households were chosen based on interviews with individual patients and represented places with potential contact with sweat, urine or vomit contaminated with residues of ADs. Samples from similar potentially affected places (bathrooms, toilets, kitchens, sanitary places) were collected also in hospices and retirement homes. Surface wipe samples were obtained by the standardized procedure as described previously (Odraska et al., 2014, 2013,2011 , Blahova 2021). Briefly, surfaces were wiped with swabs moistened with acetate buffer $(20 \mathrm{mM}$, pH 4$)$ from the marked spots (30x30cm) and stored at $-20^{\circ} \mathrm{C}$ until extraction. Field blanks (moistened swab) and quality of extraction controls (swab spiked with quality control sample) were processed together with collected wipe samples. Before quantitative analyses, samples were extracted with acetate buffer by sonication (45 min), centrifugated, and an aliquot of the supernatant was directly used for analyses of organic ADs by LC-MS/MS. For Pt, $0.4 \mathrm{~mL}$ aliquot of the supernatant was diluted with $2 \mathrm{ml}$ of $3 \%$ hydrochloric acid and analyzed by ICP-MS.

Table 1. Characteristics of the participants from the study of patient households. The table shows details on therapy received as well as numbers of total and positive samples collected in individual patient homes during the First sampling (i.e. patients actively undergoing chemotherapy), and the Second control sampling (6 or more months after the last chemotherapy cycle).

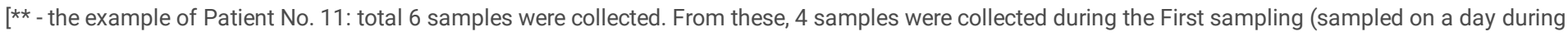
Therapy B, which was the 3rd day after the first cycle of PX, and this day corresponded to the 24th day after the last - 4th - treatment cycle of CP/DOX). Two of these 4 samples were positive for $\mathrm{CP}$ and negative for PX. The remaining 2 samples (both negative) were collected during the Second control sampling].

\begin{tabular}{|c|c|c|c|c|c|c|c|c|c|c|c|c|}
\hline \multirow[b]{3}{*}{$\begin{array}{l}\text { Participant } \\
\text { ID }\end{array}$} & \multirow[b]{3}{*}{$\begin{array}{l}\text { Age / } \\
\text { Gender }\end{array}$} & \multirow[b]{3}{*}{$\begin{array}{l}\text { Total } \\
\text { number } \\
\text { of wipe } \\
\text { samples }\end{array}$} & \multicolumn{9}{|c|}{ First sampling } & \\
\hline & & & \multicolumn{5}{|c|}{ Therapy A (CP, DOX, EPI, FU, IRI, Pt) } & \multicolumn{5}{|c|}{ Therapy B (PX, Pt) } \\
\hline & & & ADs & $\begin{array}{l}\text { Administered } \\
\text { doses (mg) }\end{array}$ & $\begin{array}{l}\text { Sampling } \\
\text { day / the } \\
\text { last cycle } \\
\text { before } \\
\text { sampling }\end{array}$ & $\begin{array}{l}\text { Number } \\
\text { of wipe } \\
\text { samples }\end{array}$ & $\begin{array}{l}\text { Positive } \\
\text { samples }\end{array}$ & ADs & $\begin{array}{l}\text { Administered } \\
\text { doses (mg) }\end{array}$ & $\begin{array}{l}\text { Sampling } \\
\text { day / the } \\
\text { last cycle } \\
\text { before } \\
\text { sampling }\end{array}$ & $\begin{array}{l}\text { Number } \\
\text { of wipe } \\
\text { sample }\end{array}$ & $\begin{array}{l}\mathrm{F} \\
\mathrm{S}\end{array}$ \\
\hline 1 & $68 / F$ & 23 & CP/DOX & $1000 / 100$ & $\begin{array}{l}3 / 1,6 / 2 \\
31 / 4\end{array}$ & 14 & 11 & $\mathrm{PX}$ & 133 & $3 / 2$ & 5 & 1 \\
\hline 2 & $39 / F$ & 12 & CP/DOX & $858 / 86$ & $3 / 4,51 / 4$ & 8 & 8 & $\mathrm{PX} / \mathrm{Pt}$ & $115 / 235$ & $2 / 6$ & 4 & 3 \\
\hline 3 & $48 / F$ & 9 & CP/DOX & $1000 / 100$ & $1 / 3$ & 4 & 4 & - & - & - & - & - \\
\hline 4 & $55 / F$ & 8 & CP/DOX & $990 / 99$ & $1 / 3$ & 4 & 4 & $\mathrm{PX}$ & 133 & - & - & - \\
\hline 5 & $49 / F$ & 8 & CP/DOX & 1090/109 & $10 / 3$ & 4 & 3 & - & - & - & - & - \\
\hline 6 & $35 / F$ & 8 & CP/DOX & $1100 / 110$ & $4 / 2$ & 4 & 3 & - & - & - & - & - \\
\hline 7 & $43 / F$ & 8 & CP/DOX & $984 / 98$ & $7 / 2$ & 4 & 4 & - & - & - & - & - \\
\hline 8 & $38 / F$ & 8 & CP/DOX & $1020 / 102$ & $1 / 2$ & 4 & 3 & $P X$ & 138 & - & - & - \\
\hline 9 & $34 / F$ & 9 & CP/DOX & $918 / 92$ & $1 / 3$ & 5 & 3 & $\mathrm{PX}$ & 122 & - & - & - \\
\hline 10 & $40 / F$ & 5 & CP/DOX & $1128 / 113$ & $76 / 4$ & 5 & 0 & $\mathrm{PX}$ & 151 & $6 / 9$ & 5 & 0 \\
\hline $11^{\star \star}$ & $40 / F$ & $6 * \star$ & CP/DOX & $1140 / 114$ & $24 / 4 \star \star$ & $4^{\star \star}$ & $2^{\star \star}$ & PX & 152 & $3 / 1^{\star \star}$ & 4 *夫 & 0 \\
\hline 12 & $73 / F$ & 5 & CP/DOX & $960 / 96$ & $1 / 2$ & 5 & 5 & $\mathrm{PX} / \mathrm{Pt}$ & $128 / 212$ & - & - & - \\
\hline 13 & $43 / F$ & 4 & CP/EPI & $1303 / 157$ & $29 / 4$ & 4 & 0 & $\mathrm{PX}$ & 127 & $1 / 2$ & 4 & 0 \\
\hline 14 & $42 / F$ & 4 & CP/DOX & $900 / 90$ & $44 / 4$ & 4 & 0 & $\mathrm{PX}$ & 120 & $1 / 5$ & 4 & 0 \\
\hline 15 & $37 / F$ & 4 & CP/DOX & $978 / 98$ & $2 / 2$ & 4 & 4 & $\mathrm{PX}$ & 129 & - & - & - \\
\hline 16 & $75 / M$ & 4 & $\mathrm{Pt} / \mathrm{FU} / \mathrm{IRI}$ & $135 / 3724 / 229$ & $5 / 5$ & 4 & 2 & - & - & - & - & - \\
\hline 17 & $45 / F$ & 8 & CP/DOX & $1068 / 107$ & $5 / 2$ & 4 & 3 & $\mathrm{PX}$ & 144 & - & - & - \\
\hline
\end{tabular}

2.4 Instrumental analyses of studied ADs

Liquid chromatography/tandem mass spectrometry, LC-MS/MS with Waters Acquity LC chromatograph (Waters, Manchester, U.K.) and Xevo TQ-S quadrupole mass spectrometer (Waters, Manchester, U.K.) was used for analyses of cyclophosphamide CP, 5-fluorouracil FU, paclitaxel PX, doxorubicin DOX, epirubicin EPI, irinotecan IRI, ifosphamide IF, methotrexate MET, capecitabine CAP, docetaxel DOC and gemcitabine GEM using a recently described multitarget method (Blahova et al., 2021). Analytes after ESI ionization were detected in negative and positive ion mode using tandem mass spectrometry with multiple reaction monitoring (MRM). Collision energy, cone voltage, retention time, and the lower limit of quantification (the lowest amount of analyte in the sample matrix that can be quantified; LLOQ; the signal to noise ratio $S / N>10$ ) were optimized for each analyte and are presented together with the calibration linearity and correlation coefficient in Supplementary Table S3. Data were processed by MassLynx ${ }^{\mathrm{TM}}$ software (Waters, Manchester, U.K.). Concentrations of analytes were corrected to internal standards (CP D4; FU 15N2 13C; PX D5; IRI D10; GEM 13C15N2; MET D3; CAP D11). The results were reported as picograms of ADs per square centimeter of the surface. 
Inductively coupled plasma/mass spectrometry, ICP-MS used Agilent 7700x ICP-MS system (Agilent Technologies Inc., Japan) for the analyses of total Pt concentration as a marker of Pt-based ADs (Blahova et al., 2021). Quantification was based on external calibration ( ${ }^{194} \mathrm{Pt}$ and ${ }^{195} \mathrm{Pt}$ isotopes) with the correction of signal drift and non-spectral interferences on internal standards $\left({ }^{185} \mathrm{Rh}\right.$ and $\left.{ }^{209} \mathrm{Bi}\right)$. Results are reported as pg of Pt per square centimeter of surface.

\section{Results}

\subsection{Detailed study in the patient's household}

In this pilot study, five different surfaces were wiped in the household of Patient No. 1 on 4 different days (days 3, 6, 31 and 295 after the last administration of CP/DOX therapy; cf Table 1). On days 3 and 6, all studied places were contaminated by CP. The highest concentrations were found on the surface of a dining table $\left(65.5 \mathrm{pg} / \mathrm{cm}^{2}\right)$ and a computer keyboard $\left(25.9 \mathrm{pg} / \mathrm{cm}^{2}\right) .31$ days after the last administration of CP/DOX, only low contamination was observed on the same surfaces of a dining table and keyboard. On day 295 (more than 9 months after the last treatment with CP), traces of contamination (pg/cm ${ }^{2}$ ) were still detectable on the wooden dining table. DOX was not detected in any of the studied samples. Considering the administration of PX, samples were collected on day 3 after the 2nd cycle of PX administration, and low PX contamination was detected only on the bathroom floor. No PX contamination was observed 6 months after the last PX administration (Table 2).

Table 2

$\mathrm{CP}$ and PX contamination profiles $\left(\mathrm{pg} / \mathrm{cm}^{2}\right)$ in the household of participant No. 1; "na" not analyzed; * below the respective limit of detection, <LOD.

\begin{tabular}{|c|c|c|c|c|c|}
\hline $\begin{array}{l}\text { Sampling day } \\
\text { [MM/DD/YYYY] }\end{array}$ & 08/29/2019 & 09/02/2019 & $09 / 26 / 2019$ & $12 / 05 / 2019$ & $08 / 25 / 2020$ \\
\hline $\begin{array}{l}\text { Therapy A } \\
\text { (CP; pg/cm2) }\end{array}$ & $\begin{array}{l}\text { Before therapy } \\
\text { started }\end{array}$ & $\begin{array}{l}3 \text { days after the } 1^{\text {st }} \\
\text { therapy cycle }\end{array}$ & $\begin{array}{l}6 \text { days after the } 2^{\text {nd }} \\
\text { therapy cycle }\end{array}$ & $\begin{array}{l}31 \text { days after the last } 4^{\text {th }} \\
\text { therapy cycle }\end{array}$ & $\begin{array}{l}295 \text { days after the last } 4^{\text {th }} \\
\text { therapy cycle }\end{array}$ \\
\hline Bathroom floor & $<1.1^{\star}$ & 16.9 & 13.8 & $<1.1^{\star}$ & $<1.1^{\star}$ \\
\hline Toilet floor & $<1.1^{\star}$ & 7.9 & 8.2 & $<1.1^{\star}$ & $<1.1^{\star}$ \\
\hline Kitchen desk & $<1.1^{\star}$ & 5.2 & 2.9 & $<1.1^{\star}$ & $<1.1^{\star}$ \\
\hline Dining table & $<1.1^{\star}$ & 65.5 & 20.4 & 4.9 & 1.2 \\
\hline Computer keyboard & na & na & 25.9 & 4.1 & $<1.1^{\star}$ \\
\hline $\begin{array}{l}\text { Therapy B } \\
\text { (PX; pg/cm2) }\end{array}$ & $\begin{array}{l}\text { Before therapy } \\
\text { started }\end{array}$ & & & $\begin{array}{l}3 \text { days after the } 2^{\text {nd }} \\
\text { therapy cycle }\end{array}$ & $\begin{array}{l}211 \text { days after the last } 10^{\text {th }} \\
\text { therapy cycle }\end{array}$ \\
\hline Bathroom floor & $<2.7^{\star}$ & & & $<2.7^{\star}$ & $<2.7^{\star}$ \\
\hline Toilet floor & $<2.7^{*}$ & & & 3.8 & $<2.7^{*}$ \\
\hline Kitchen desk & $<2.7^{\star}$ & & & $<2.7^{\star}$ & $<2.7^{\star}$ \\
\hline Dining table & $<2.7^{\star}$ & & & $<2.7^{\star}$ & $<2.7^{\star}$ \\
\hline Computer keyboard & na & & & $<2.7^{*}$ & $<2.7^{\star}$ \\
\hline
\end{tabular}

3.2 Monitoring of patient households, hospices, and retirement homes

Wipe samples in the patient households were taken mainly from the bathroom and toilet floors (made by tiles) and from surfaces in kitchens or living rooms, i.e. dining tables and desks (made from wooden or wood-resin composite materials). In total, 133 samples were collected in 17 patient households, including 4 samples before the therapy (only in Patient No. 1), 85 samples during the First sampling (samples from days 1-75 after the last chemotherapy treatment), and 44 samples during the Second control sampling ( 6 months, 180 days, or more after the last chemotherapy treatment). Moreover, 10 samples were collected in hospices (residential rooms, sanitary and shared public areas) and 19 samples were collected in retirement homes (residential rooms, sanitary, laundry and shared public areas).

Figure 1 provides an overview of the AD contamination in all tested samples; data are shown only for ADs that were commonly detected. Complete data set is provided in the Supplementary Materials (Supplementary Table S4), CP, Pt and PX were detected in variable concentrations namely during the First sampling in the patient households. Other studied ADs were not detected although they were administered in chemotherapies of individual patients; DOX, EPI, IRI and FU were below their respective LODs of $4.5,4.5,2.0$, and $6.9 \mathrm{pg} / \mathrm{cm}^{2}$, respectively.

Regarding CP, $67 \%$ of the samples collected during the first sampling in the patient households (57 from N=85) were positive for CP; i.e. above the LOD for CP of $1.1 \mathrm{pg} / \mathrm{cm}^{2}$. During the second control sampling, the majority of the samples were below LOD except for 4 households, where trace CP concentrations close to LOD were detected ranging $1.2-6.4 \mathrm{pg} / \mathrm{cm}^{2}$. CP was below LOD in all samples collected in the hospices or retirement homes (Figure 1).

Except for one patient (No. 16), all participants received CP as a part of Therapy A (cf Table 1). The CP surface contamination during the first sampling ranged between < LOD up to maximum $511.7 \mathrm{pg} / \mathrm{cm}^{2}$ (armchair and kitchen table, patient No 12) with median and average values of 3.4 and $21.1 \mathrm{pg} / \mathrm{cm}^{2}$, respectively. Maxima in $\mathrm{CP}$ contamination were observed during the first few days after patients received the last chemotherapy (see Fig. 2) with the 
decreasing temporal trend on all examined surfaces (Fig. 2A and 2B). Concerning the statistical significance, elevated $\mathrm{CP}$ values on the floors were observed in samples collected on days 1-6 compared to samples collected later during the first sampling, i.e. on days $7+(p=0.036$, Student's t-test).

Comparing the contamination of different types of surfaces, $74 \%$ of floors in bathrooms or near the toilets were positive for $\mathrm{CP}$ with maximum $235.7 \mathrm{pg} / \mathrm{cm}^{2}$. Desktops from kitchens or living rooms were positive for CP in $67 \%$ of cases with maximum $511.7 \mathrm{pg} / \mathrm{cm}^{2}$ (Fig. 2). The median (3.9 and $4.5 \mathrm{pg} / \mathrm{cm}^{2}$, respectively) and average $\mathrm{CP}$ contamination (16.6 and $27.7 \mathrm{pg} / \mathrm{cm}^{2}$, respectively) were comparable at both floors and desktops.

Six participants received a follow-up PX treatment (see Therapy B in Table 1), and there were only 2 positive samples $\left(2.9\right.$ and $\left.3.8 \mathrm{pg} / \mathrm{cm}^{2}\right)$ out of total $\mathrm{N}=26$ collected during the First sampling ( $L O D$ for $P X=2.5 \mathrm{pg} / \mathrm{cm}^{2}$ ). No sample collected during the second control sampling was positive for PX (see

Supplementary Table S4 for all details).

The analyses of Pt in two houses of patients that were treated with Pt-based drugs revealed that five out of total $\mathrm{N}=8$ samples (63\%) were positive during the first sampling (> LOD $0.17 \mathrm{pg} / \mathrm{cm}^{2}$ ). Pt was found mostly on the floors of bathrooms and toilets. Pt contamination ranged from < LOD up to $2.7 \mathrm{pg} / \mathrm{cm}^{2}$ with median and average of 0.3 and $0.7 \mathrm{pg} / \mathrm{cm}^{2}$, respectively. Low Pt level $\left(0.28 \mathrm{pg} / \mathrm{cm}^{2}\right)$ was found also in a single desktop sample (Patient No 2). One of the samples collected during the second control sampling was also found positive for Pt but at very low concentration $0.5 \mathrm{pg} / \mathrm{cm}^{2}$ (patient No. 2 ; single sample from the bathroom floor).

Regarding the hospices, Pt-contamination (> LOD $0.17 \mathrm{pg} / \mathrm{cm}^{2}$ ) was found in three samples - in a sanitary room and residential room of Hospice 1 and a bathroom floor in Hospice 2 (Fig. 1). Compared to the patient homes (discussed above), higher Pt-contamination was detected reaching up to 15.9 pg/cm² (Hospice 2, bathroom floor of a resident with colorectal carcinoma in palliative care; previously received a therapy that included oxali-Pt combined with FU, CAP and IRI). The 19 samples collected in the two monitored retirement houses were mostly negative for 12 studied ADs. Low levels of IF (1.3 and 3.3 $\mathrm{pg} / \mathrm{cm}^{2}$ ) were found in two samples collected on the floor in the apartment of a former resident that was previously diagnosed and treated for myeloma but passed away in 2018, i.e. two years before actual monitoring. Further, trace contamination by MET $\left(3.3 \mathrm{pg} / \mathrm{cm}^{2}\right)$ was detected in a sample taken from the floor in the apartment of resident undergoing active oncology treatment with methotrexate in tablet form.

\section{Discussion}

The contamination of hospitals and pharmacies by ADs and related occupational exposures and risks have been studied before and indicated potential health hazards during life-long exposures (NIOSH, n.d.) (ISOPP 2007). Much less attention has been paid so far to potential contamination in the households of patients treated with $A D$ chemotherapies despite the increasing trends in using take-home anticancer therapies (Pardhan at al., 2020). The present research aids to this underestimated problem where the studies of $A D$ indoor contamination outside of hospitals or pharmacies are very rare. To our knowledge, there are only 3 reports. Two papers documented a study from Japan that considered 3 homes of patients treated with AD chemotherapy and reported CP residua on toilet or bathroom surfaces ranging $30-7340 \mathrm{pg} / \mathrm{cm}^{2}$ (Yuki et al., 2013; 2015). The second study from Germany investigated homes of 13 patients and reported contamination by Pt ranging $0.02-42.5 \mathrm{pg} / \mathrm{cm}^{2}$ and CP up to $283.3 \mathrm{pg} / \mathrm{cm}^{2}$ (Böhlandt et al., 2017). This latter study showed CP residues mostly on toilet surfaces and also in the urine of family members (Böhlandt et al., 2017).

In the present paper, we focused on both the traditionally studied floors that are a major issue in healthcare facilities (Meijster et al., 2006) but also on other surfaces in patient households that might be contaminated e.g. by the patient sweat such as the tables, chairs or other desktops. Our samples were collected during the summertime (May to September period in Europe) when the contact with sweaty skin is the most intensive providing thus the indication of the highest possible exposure situations.

In agreement with previous studies, CP and Pt were the most important exposures markers (Acampora et al., 2005) and were detected in high frequencies during the chemotherapy of patients as capture in the first sampling (66.6\% positive for $\mathrm{CP}$ and $63 \%$ positive for Pt) Besides, PX was also rarely detected with $8 \%$ of samples positive. Correspondingly to studies of (Yuki et al., 2013; 2015 and Böhlandt et al., 2017), floors in toilets and bathrooms were often contaminated due to possible spills of patient excretion (maxima CP $235.7 \mathrm{pg} / \mathrm{cm}^{2}$, Pt $2.7 \mathrm{pg} / \mathrm{cm}^{2}$ and PX $3.8 \mathrm{pg} / \mathrm{cm}^{2}$ ). However, we further observed high frequency $(67.1 \%$ positive) of CP contamination also on desktops in kitchens and living rooms with actually the highest detected $\mathrm{CP}$ concentration in the present study $511.7 \mathrm{pg} / \mathrm{cm}^{2}$.

The floor contamination by ADs observed in the households has been much lower in comparison with available pharmacy and hospital studies where accidental values higher than $100 \mathrm{ng} / \mathrm{cm}^{2}$ (for CP) or higher than $10 \mathrm{ng} / \mathrm{cm}^{2}$ (Pt) were reported (Kopp et al., 2013; Schierl et al., 2009; Turci et al., 2003). Our recent study concerned 26 hospitals in the Czech Republic and showed median contamination of hospital toilet floors being $30,200,10 \mathrm{pg} / \mathrm{cm}^{2}$ for $\mathrm{CP}(\mathrm{N}=$ 25), Pt ( $=18)$ and PX ( $=25)$, respectively (Bláhová et al., 2021). Interestingly, the median values observed in the present study for $\mathrm{CP}$ (16.6 pg/cm for floors) were closely comparable, and the immediate exposures thus are similar in both occupational and household settings. Indeed, the safe occupational limit of $100 \mathrm{pg} / \mathrm{cm}^{2}$ derived for CP in hospitals (Sessink, 2011) was exceeded in two households with the highest CP contamination, i.e. at Participant No. 12 $\left(511.7 \mathrm{pg} / \mathrm{cm}^{2}\right.$ on the surface of a chair in the living room) and Participant No. 3 living together with a child (235.7 pg/cm² on the bathroom floor). It should, however, be noted that the occupational exposures last much longer compared to rather episodical situations when family members are potentially exposed to ADs during chemotherapy of the patients. This was also confirmed during the Second control sampling in the present study (6 or more months posttreatment) when CP was below LOD in 6 out of 11 households that were found CP-positive during the First sampling.

Our study further showed significantly elevated contaminations of homes by CP especially during the first six days after the chemotherapy. This is in agreement with the previous study that showed the release of unmetabolized AD during five days post-treatment (Yuki et al., 2015). Also, (ISOPP 2007) 
highlights that precautions should be taken for manipulation with body fluids of patients during 7 days post-treatment.

Further, frequent and long-residing contaminations by CP were detected on the desktop surfaces during both the First and the Second control samplings. Indeed, 3 out of the 4 CP-positive samples collected in the 2 nd control sampling were from wooden surfaces of dining tables treated with a surface protecting wax or varnish layers (Supplementary Fig. S1). This highlights that the patient sweat is an important source of secondary contamination and that the wax/varnish-treated surfaces that are often in direct contact with the patient may serve as long-term deposits of AD contamination. This observation is supported by our recent observations of CP mobilization from the wax-treated Marmoleum floors (Bláhová et al., 2021) as well as by other studies (ISOOP 2007). On the contrary, inert materials such as tiles used in bathrooms or toilets can easily be washed out keeping thus contamination under the control. It should also be mentioned that the patient questionnaire survey did not indicate any correlations between the levels of contamination and cleaning practices in individual households (see also Supplementary Materials, Table S2).

Besides CP, Pt contamination was observed in patient households (63\% samples positive during the first sampling) but with a low median of 0.2 pg/cm ${ }^{2}$ comparable to the available German household study (Böhlandt et al., 2017). The observed concentrations are two orders of magnitude lower than Pt contamination in hospitals including the Czech Republic, where long-term monitoring data indicate a median of $200 \mathrm{pg} / \mathrm{cm}^{2}$ (Bláhová et al., 2021). Here it should be critically noted that the analyses of total Pt, which is a common approach in the ADs monitoring studies (Böhlandt et al., 2017; Konate et al., 2011; Schierl et al., 2009; Yoshida et al., 2013) do not allow to discriminate other different sources of Pt such as occupation (e.g. metallurgy), dental materials or breast implants (Schierl et al., 2014). Surface Pt concentrations below $0.1 \mathrm{pg} / \mathrm{cm}^{2}$ are considered as environmental background while higher levels indicate contamination (Böhlandt et al., 2017). Although our study does not allow us to draw strong conclusions on potential risks associated with Pt in households, low concentrations - namely in the second control sampling when Pt was below LOD in almost all samples - suggest that possible risks of Pt (and also PX) are much lower compared to $\mathrm{CP}$.

To our knowledge, this one of the first studies that investigated eventual AD contamination in hospices and retirement homes. During our pilot monitoring of hospices, no patients actively receiving chemotherapy were hosted in the studied facilities. Nevertheless, screening for 12 ADs in hospices showed elevated concentrations of Pt reaching up to $15.9 \mathrm{pg} / \mathrm{cm}^{2}$, which is considerable value even in comparison to the situation in some hospitals (Kopp et al., 2013). In one of the hospices, this contamination was traced back to a former oncology patient with diagnosed colorectal cancer that was previously treated with oxali-Pt containing chemotherapy. In this context, studies showed that Pt might accumulate in a body during the lifetime through, for example, covalent binding to sulfhydryl protein groups (Zhang et al., 2020). Correspondingly, levels of Pt up to 1000-times higher compared to the control population were observed in patients 20 years post-Pt-chemotherapy (Chovanec et al., 2017). However, there is still a lack of detailed information on the pharmacokinetics of Pt-based drugs as recently highlighted by a large difference in the accumulation of cis-Pt and oxali-Pt in the patients (Zhang et al., 2020).

In the monitored retirement homes, low contamination was expected as the available information about eventual AD-treated patients was poor. The management of the retirement homes estimated that they usually host a maximum up to 3 oncology patients per year, more information about clients eventually treated with chemotherapy was not available. Nevertheless, IF was detected in two of the floor samples (low level with max $3.3 \mathrm{pg} / \mathrm{cm}^{2}$ ) from the apartment that was formerly used by a resident with myeloma that passed away in 2018, i.e. two years before actual monitoring in 2020 . Also, MET (3.3 $\mathrm{pg} / \mathrm{cm}^{2}$ ) was detected in the apartment (floor sample) of the resident undergoing active oncology treatment with orally administered methotrexate. To our knowledge, the information on ADs in retirement or nursing homes is extremely rare. Only one study of nursing homes in the Netherlands reported that their clients received chemotherapy, mostly in outpatient clinics (Meijster et al., 2006). This study assessed dermal exposures of the staff to ADs (through resident washing or the in-house cleaning processes) and concluded on the low frequency of exposure and consequently lower risks for nursing home staff compared to e.g. personnel in hospitals (Meijster et al., 2006).

Although we are aware of the limitations of our pilot study, there are several lines of evidence indicating that Pt may reside in the body of patients for a long time, and it may become released during later life stages posing thus hazards to family members or staff in retirement houses or hospices. Also, detection of IF on the floor of the retirement house two years after the latest potentially confirmed source might raise a concern of long-term accumulation (and release) of ADs from indoor materials (Bláhová et al., 2021). Further research studies in these directions might clarify the hypotheses.

Our findings indicate that the households of oncology patients may be contaminated by ADs. However, the information about potential AD hazards provided by the clinicians to patients was not sufficient, and the availability of preventive measures in the studied households was limited (see the questionnaire survey in Supplementary Table S2). For example, only 4 out of 17 participants had more than one toilet in the house, and a separate usage of a dedicated toilet by an oncology patient was thus generally limited. On the other hand, 10 participants lived together with susceptible individuals like small children. Consequently, we prepared written safety guidelines that specifically target patients and their family members that include practical and understandable recommendations on prevention, cleaning, handling of potentially contaminated materials such as laundry, etc. This flyer was inspired by other materials from Australia and Canada (e.g. https://www.health.qld.gov.au; http://www.bccancer.bc.ca), and it is systematically distributed to patients of the participating hospital, Masaryk Memorial Cancer Institute in Brno, as well as to other hospitals in the Czech Republic (the flyer in Czech is available at https://www.cytostatika.cz/index.php? $\mathrm{pg}=$ pro-pacienty). The content and format of the flyer were also commented on by the patients enrolled in the present study, and the perception of the flyer was largely positive.

\section{Conclusions}

This is one of the first studies investigating the contamination by ADs in indoor environments outside of hospitals or pharmacies. The present study showed that patients treated with chemotherapy may serve as a source of contamination for their households, representing thus a risk to sensitive family members such as children or elderly people. Carcinogenic CP was commonly found at relatively high concentrations, especially during the first 6 days after the chemotherapy. Sweat seems to be a major medium for the spread of the contamination - high and long-time persisting CP levels were found on various 
desktops including kitchen tables. Other studied ADs such as DOX, EPI, PX, Pt, IRI and FU seem to be of lower concern. The first pilot studies in hospices and retirement homes indicated rather lower exposure risks of the personnel but pointed to potential long-lasting contamination by $\mathrm{Pt}$ or some other persistent $\mathrm{ADs}$ such as IF.

\section{Declarations}

\section{Ethics approval and consent to participate}

The study was approved by the Ethical Committee of the Masaryk Memorial Cancer Institute hospital in Brno, CZ. All participants enrolled gave their written consent.

\section{Consent for publication}

Not applicable - no personal data included in the manuscript.

\section{Availability of data and material}

Full data are provided in the Supplementary materials, and can further details can be obtained upon email request to the corresponding author (ludek.blaha@recetox.muni.cz)

\section{Competing interests}

Authors declare no competing interests.

\section{Authors'contributions}

LucB designed the study, validate methods and performed analyses, evaluated results, and prepared the manuscript. JK developed methods and analyzed Pt in studied samples, contributed to manuscript writing. LD contributed to the design of the study, contributed to sampling and manuscript writing. SK contributed to the design of the study, contributed to the interpretation of the results. TK runs the extraction and contribute to manuscript writing. LudB contributed to the study design, method development, data processing, data interpretation, and manuscript writing.

\section{Funding}

The research has been supported by the Czech Health Research Council project (NV18-09-00188), and the research infrastructure projects from the Czech Ministry of Education (LM2018121; CZ.02.1.01/0.0/0.0/17_043/0009632).

\section{Acknowledgments}

We are grateful to all patients participating in this study, technicians from MOÚ for assistance with sampling of patient homes, management and personnel of hospices and retirement homes for their cooperation and support.

\section{References}

1. Acampora A, Castiglia L, Miraglia N, Pieri M, Soave C, Liotti F, Sannolo N (2005) A case study: Surface contamination of cyclophosphamide due to working practices and cleaning procedures in two Italian hospitals. Ann Occup Hyg 49:611-618. https://doi.org/10.1093/annhyg/mei029

2. Astrakianakis G, Jeronimo M, Griffiths A, Colombo M, Kramer D, Demers PA, Hon CY (2020) The application of novel field measurement and field evaluation protocols for assessing health care workers' exposure risk to antineoplastic drugs. J Occup Environ Hyg 17:373-382. https://doi.org/10.1080/15459624.2020.1777296

3. Blahova L, Dolezalova L, Kuta J, Kozáková Š, Bláha L (2020) Hospitals and Pharmacies as Sources of Contamination by Cytostatic Pharmaceuticals: Long-Term Monitoring in the Czech Republic. In: Heath E, Isidori M, Kosjek T, Filipič M (eds) Fate and Effects of Anticancer Drugs in the Environment. Springer Nature Switzerland AG, pp 57-70. https://doi.org/10.1007/978-3-030-21048-9

4. Bláhová L, Kuta J, Doležalová L, Kozáková Š, Krovová T, Bláha L (2021) The efficiency of antineoplastic drug contamination removal by widely used disinfectants-laboratory and hospital studies. Int Arch Occup Environ Health. https://doi.org/10.1007/s00420-021-01671-5

5. Böhlandt A, Sverdel Y, Schierl R (2017) Antineoplastic drug residues inside homes of chemotherapy patients. Int J Hyg Environ Health 220:757-765. https://doi.org/10.1016/j.jijheh.2017.03.005

6. Chauchat L, Tanguay C, Caron N, Gagné S, Labrèche F, Bussières J (2019) Surface contamination with ten antineoplastic drugs in 83 Canadian centers. J Oncol Pharm Pract 25:1089-1098. https://doi.org/10.1177/1078155218773862

7. Cherrie JW, Hutchings S, Gorman Ng M, Mistry R, Corden C, Lamb J, Sánchez Jiménez A, Shafrir A, Sobey M, Van Tongeren M, Rushton L (2017) Prioritising action on occupational carcinogens in Europe: A socioeconomic and health impact assessment. Br J Cancer 117:274-281.

https://doi.org/10.1038/bjc.2017.161

8. Chovanec M, Abu Zaid M, Hanna N, El-Kouri N, Einhorn LH, Albany C (2017) Long-term toxicity of cisplatin in germ-cell tumor survivors. Ann Oncol 28:2670-2679. https://doi.org/10.1093/annonc/mdx360

9. Connor TH, McDiarmid MA (2006) Preventing Occupational Exposures to Antineoplastic Drugs in Health Care Settings. CA Cancer J Clin 56:354-365. https://doi.org/10.3322/canjclin.56.6.354 
10. Dranitsaris G, Johnston M, Poirier S, Schueller TT, Savage T, Milliken DD, Green E, Evans W, Zanke B (2005) Are health care providers who work with cancer drugs at an increased risk for toxic-events? A systematic review and meta analysis of the literature. J Clin Oncol Off J Am Soc Clin Oncol 23:548S-548S

11. Fleury-Souverain S, Mattiuzzo M, Mehl F, Nussbaumer S, Bouchoud L, Falaschi L, Gex-Fabry M, Rudaz S, Sadeghipour F, Bonnabry P (2015) Evaluation of chemical contamination of surfaces during the preparation of chemotherapies in 24 hospital pharmacies. Eur J Hosp Pharm 22:333-341. https://doi.org/10.1136/ejhpharm-2014-000549

12. Fransman W, Vermeulen R, Kromhout H (2005) Dermal exposure to cyclophosphamide in hospitals during preparation, nursing and cleaning activities. Int Arch Occup Environ Health 78:403-412. https://doi.org/10.1007/s00420-004-0595-1

13. Gabay, M., 2014. USP < 800>: Handling hazardous drugs. Hosp Pharm 49:811-812.

14. Hon C-Y, Teschke K, Shen H, Demers Pa, Venners S (2015) Antineoplastic drug contamination in the urine of Canadian healthcare workers. Int Arch Occup Environ Health 9. https://doi.org/10.1007/s00420-015-1026-1

15. IARC: International Agency for Research on Cancer. IARC Monographs on the evaluation of carcinogenic risks to humans - Volume $100 \mathrm{~A}$ Pharmaceuticals, https://mono- graphs.iarc.fr/wp-content/uploads/2018/06/ mono100A.pdf (accessed 2 February 2019)

16. ISOP: International Society of Oncology Pharmacy Practicioners Standards Committee (2007) ISOPP standards of practice. Safe handling of cytotoxics. J Oncol Pharm Pract 13 Suppl:1-81. doi:10.1177/1078155207082350

17. Jeronimo M, Colombo M, Astrakianakis G, Hon CY (2015) A surface wipe sampling and LC-MS/MS method for the simultaneous detection of six antineoplastic drugs commonly handled by healthcare workers. Anal Bioanal Chem 407:7083-7092. https://doi.org/10.1007/s00216-015-8868-y

18. Kiffmeyer TK, Tuerk J, Hahn M, Stuetzer H, Hadtstein C, Heinemann A, Eickmann U (2013) Application and assessment of a regular environmental monitoring of the antineoplastic drug contamination level in pharmacies-the MEWIP project. Ann Occup Hyg 57:444-455.

https://doi.org/10.1093/annhyg/mes081

19. Konate A, Poupon J, Villa A, Garnier R, Hasni-Pichard H, Mezzaroba D, Fernandez G, Pocard M (2011) Evaluation of environmental contamination by platinum and exposure risks for healthcare workers during a heated intraperitoneal perioperative chemotherapy (HIPEC) procedure. J Surg Oncol 103:6-9. https://doi.org/10.1002/jso.21740

20. Kopp B, Schierl R, Nowak D (2013) Evaluation of working practices and surface contamination with antineoplastic drugs in outpatient oncology health care settings. Int Arch Occup Environ Health 86:47-55. https://doi.org/10.1007/s00420-012-0742-z

21. Kromhout H, Hoek F, Uitterhoeve R, Huijbers R, Overmars RF, Anzion R, Vermeulen R (2000) Erratum: Postulating a dermal pathway for exposure to antineoplastic drugs among hospital workers. Applying a conceptual model to the results of three workplace surveys (Annals of Occupational Hygiene (2000) 44 (551-560) PII: S003487800000508). Ann. Occup. Hyg. 44, 551-560

22. Kümmerer K, Haiß A, Schuster A, Hein A, Ebert I (2016) Antineoplastic compounds in the environment-substances of special concern. Environ Sci Pollut Res 23:14791-14804. https://doi.org/10.1007/s11356-014-3902-8

23. Meijster T, Fransman W, Veldhof R, Kromhout H (2006) Exposure to antineoplastic drugs outside the hospital environment. Ann Occup Hyg 50:657-664. https://doi.org/10.1093/annhyg/mel023

24. NIOSH, n.d. Preventing Occupational Exposure to Antineoplastic and Other Hazardous Drugs in Health Care Settings [citado 15-04-2015]. Disponible en: http://www.cdc.gov/niosh/docs/2004-165/. NIOSH Alert, Cincinnati

25. Odraska P, Dolezalova L, Kuta J, Oravec M, Piler P, Blaha L (2013) Evaluation of the efficacy of additional measures introduced for the protection of healthcare personnel handling antineoplastic drugs. Ann Occup Hyg 57:240-250. https://doi.org/10.1093/annhyg/mes057

26. Odraska P, Dolezalova L, Piler P, Oravec M, Blaha L (2011) Utilization of the solid sorbent media in monitoring of airborne cyclophosphamide concentrations and the implications for occupational hygiene. J Environ Monit 13:1480-1487. https://doi.org/10.1039/c0em00660b

27. Odraska P, Dolezalova PharmD L, Kuta J, Oravec M, Piler P, Synek PharmD S, Blaha L, Dolezalova L, Synek S (2014) Association of Surface Contamination by Antineoplastic Drugs With Different Working Conditions in Hospital Pharmacies Association of Surface Contamination by Antineoplastic Drugs With Different Working Conditions in Hospital Pharmacies. Arch Environ Occup Health 693:148-158. https://doi.org/10.1080/19338244.2013.763757

28. Pardhan A, Vu K, Gallo-Hershberg D, Forbes L, Gavura S, Kukreti V (2021) Evolving Best Practice for Take-Home. Cancer Drugs JCO Oncology Practice 17(4):e526-e536. https://doi.org/10.1200/OP.20.00448

29. Power LA, Coyne JW, Hawkins B (2018) ASHP guidelines on handling hazardous drugs. Am J Heal Pharm 75:1996-2031. https://doi.org/https://doi.org/10.2146/ajhp050529

30. Roland C, Caron N, Bussières JF (2017) Multicenter study of environmental contamination with cyclophosphamide, ifosfamide, and methotrexate in 66 canadian hospitals: A 2016 follow-up study. J Occup Environ Hyg 14:650-658. https://doi.org/10.1080/15459624.2017.1316389

31. Schierl R, Böhlandt A, Nowak D (2009) Guidance values for surface monitoring of antineoplastic drugs in german pharmacies. Ann Occup Hyg 53:703711. https://doi.org/10.1093/annhyg/mep050

32. Schierl R, Lemmer A, Bö̈hlandt A, Friedl L, Haneder S, Nowak D (2014) Silicone implants - a possible confounder for urinary platinum background concentrations? Environ Res 132:269-272. https://doi.org/10.1016/j.envres.2014.04.017

33. Sessink PJ (2011) Environmental contamination with cytostatic drugs: past, present and future. Saf. Considerations Oncol. Pharm. Special Ed, 3-5

34. Sottani C, Grignani E, Oddone E, Dezza B, Negri S, Villani S, Cottica D (2017) Monitoring surface contamination by antineoplastic drugs in Italian hospitals: Performance-based hygienic guidance values (HGVs) Project. Ann Work Expo Heal 61:1-9. https://doi.org/10.1093/annweh/wxx065 
35. Turci R, Sottani C, Spagnoli G, Minoia C (2003) Biological and environmental monitoring of hospital personnel exposed to antineoplastic agents: A review of analytical methods. J Chromatogr B 789:169-209

36. Yoshida J, Koda S, Nishida S, Nakano H, Tei G, Kumagai S (2013) Association between occupational exposure and control measures for antineoplastic drugs in a pharmacy of a hospital. Ann Occup Hyg 57:251-260. https://doi.org/10.1093/annhyg/mes061

37. Yuki M, Sekine S, Takase K, Ishida T, Sessink PJ (2013) Ex- posure of family members to antineoplastic drugs via excreta of treated cancer patients. Journal of Oncology Pharmacy Practice 19:208-217. doi:10.1177/1078155212459667

38. Yuki M, Ishida T, Sekine S (2015) Secondary Exposure of Family Members to Cyclophosphamide After Chemotherapy of Outpatients With Cancer: A Pilot Study. Oncol Nurs Forum 42:665-671. https://doi.org/10.1188/15.0NF.42-06AP

39. Zhang Y, Zheng J, Jiang Y, Huang X, Fang L (2020) Neglected, Drug-Induced Platinum Accumulation Causes Immune Toxicity. Front Pharmacol 11:1-7. https://doi.org/10.3389/fphar.2020.01166

\section{Figures}

CP

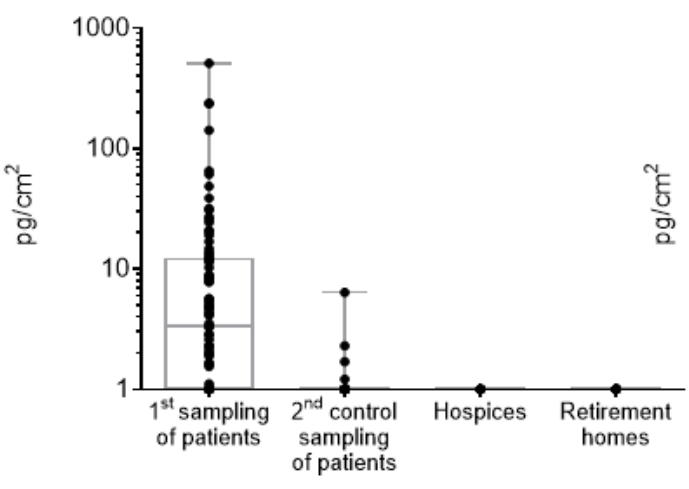

Pt

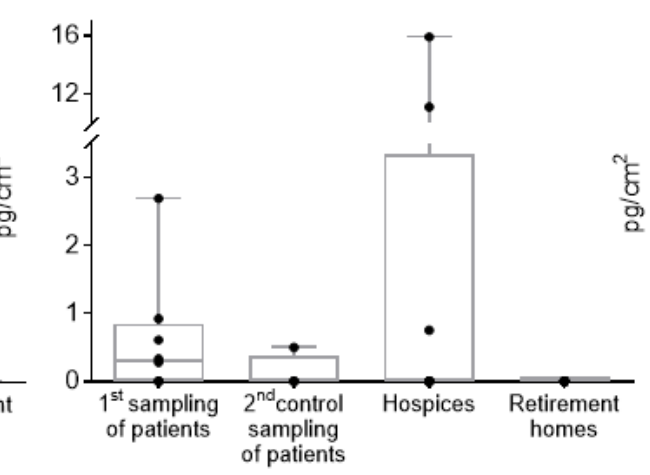

PX

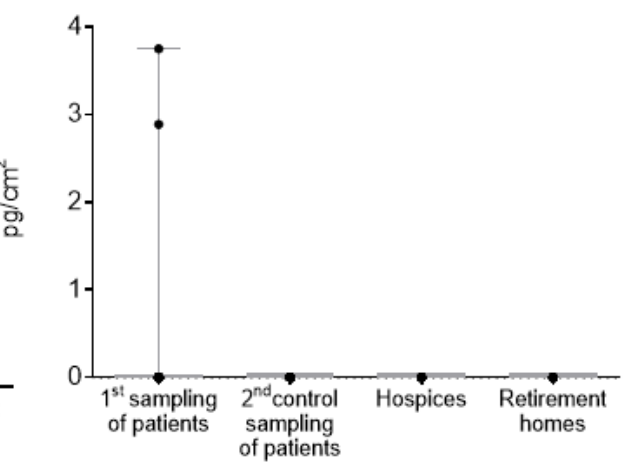

Figure 1

Profiles of ADs contamination in patient households during the First sampling and the Second control sampling compared to concentrations detected in the hospices and retirement homes. Graphs show individual data points with median and 25-75 percentile range (box), minimum-maximum (error bars).
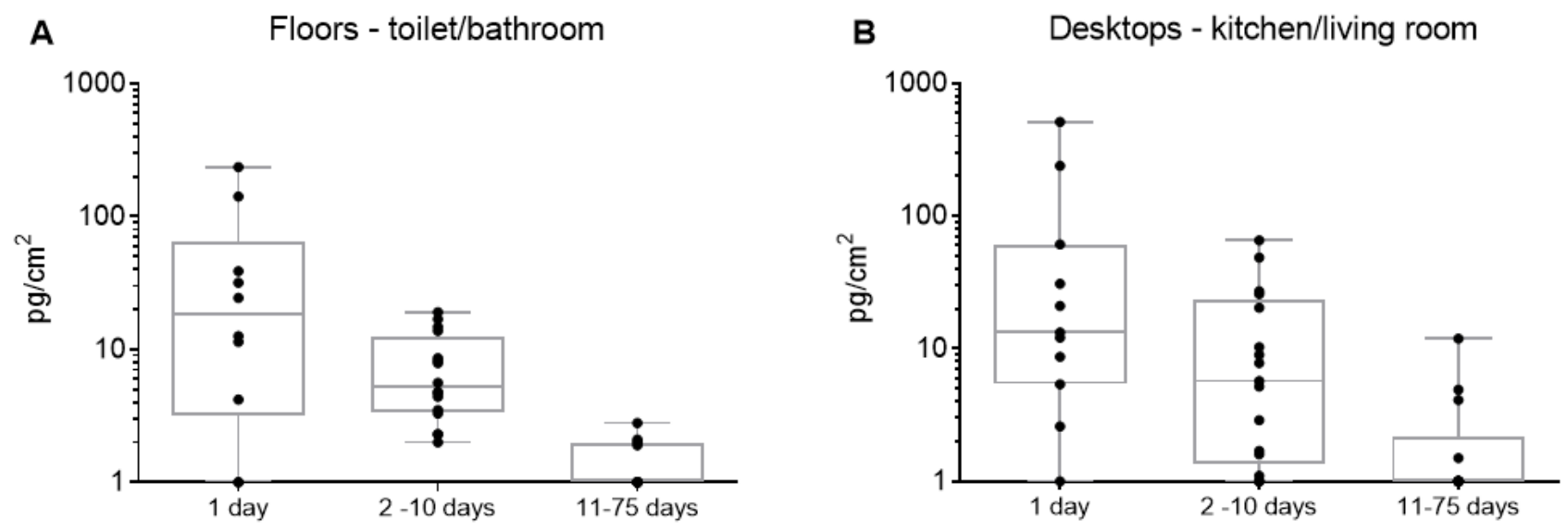

Figure 2

CP contamination of different surfaces in patient households during the First sampling. A - floors in the bathroom and toilets; B - desktop samples (tables, chairs, desks) collected in living rooms and kitchens. Graphs show individual data points with median and 25-75 percentile range (box), minimum-maximum (error bars).

\section{Supplementary Files}

This is a list of supplementary files associated with this preprint. Click to download.

- SUPPLEMENTARYMATERIALS.docX 